more elevated point, the apparent colour of the spray became bluish.

September 5

\section{Circular Rainbow seen from a Hill-top}

Noticing a communication in NATURE (p. 36r) regarding the phenomenon of a circular rainbow, I thought it worth while to mention a case which lately came under my observation. Standing on a point of rock just epposite the beautiful falls of Montmorenci, Quebec, I was surprised to see a rainbow in the form of a circle passing through my feet. The spray from the falls was being blown into a deep cove in front of me, and the sun was high in the heavens behind. The primary was well defined and very beautiful ; the secondary was faint. I understand that the conditions for seeing this circular rainbow are not often favourable at Montmorenci ; still it may not be amiss to advise intending visitors not to stop at the bottom of the steps which lead down below the falls, but to clamber over the rocks as near the water as possible.

Montreal, August 28

\section{Intelligence in Frogs}

$\Lambda$ FRIEND in Scotland has a small lake in his grounds, which are surrounded by a high wall. At the bottom of the lake is a sluice by which the water can be let off into a burn below the grounds. A few weeks ago the lady of the house was walking down the road outside the wall towards the burn when, to her astonishment, she met a multitude of frogs making their way up the road, which makes a considerable detour, to the gate leading into the grounds. On inquiry she found that the lake had that morning been emptied through the sluice, and it was plain that these were frogs which, having been carried down with the water to the burn, were now making their way back to their old home. By what instinct did they know that the long road led to the point from which the short one had started? $B$. W. S.

September 3

\section{THE TEMPERATURE OF THE SOLAR SURF ACE}

THE power developed by the sun motor, recorded in NATURE, vol. xxix. p. 217 , has established relations between diffusion and energy of solar radiation. which prove that the temperature of the surface of the sun is extremely high. I have, therefore, during the summer solstice of 1884 , carried out an experimental investigation for the purpose of demonstrating the temperature of the solar surface corresponding with the temperature transmitted to the sun motor. Referring to the illustrations previously published, it will be seen that the cylindrical heater of the sun motor, constructed solely for the purpose of generating steam or expanding air, is not well adapted for an exact determination of the amount of surface exposed to the action of the reflected solar rays. It will be perceived on inspection that only part of the bottom of the cylindrical heater of the motor is acted upon by the reflected rays, and that their density diminishes graciually towards the sides of the vessel; also that owing to the imperfections of the surface of the reflecting plates the exact course of the terminal rays cannot be defined. Consequently, the most important point in the investigation, namely, the area acted upon by the reflected radiant heat, cannot be accurately determined. I have accordingly constructed an instrument of large dimensions, a polygonal reflector (see Fig. I), composed of a series of inclined mirrors, and provided with a central heater of conical form, acted upon by the reflected radiation in such a manner that each point of its surface receives an equal amount of radiant heat in a given time. The said reflector is contained within two regular polygonal planes twelve inches apart, each having ninety-six sides, the perimeter of the upper plane corresponding with a circle of eight feet diameter, that of the lower plane being six feet. The corresponding sides of these planes are connected by flat taper mirrors composed of thin glass silvered on the out- side. When the reflector faces the sun at right angles, each mirror intercepts a pencil of rays of 32.61 square inches section, hence the entire reflecting surface receives the radiant heat of an annular sunbeam of $32.61 \times 96=3130$ square inches section. It should be observed that the area thus stated is oor I less than the total foreshortened superficies of the ninety-six mirrors if sufficiently wide to come in perfect contact at the vertices. Fig. 2 represents a transverse section of the instrument as it appears when facing the sun; the direct and reflected rays being indicated by dotted lines. The reflector and conical heater are sustained by a flat hub and eight radial spokes bent upwards towards the ends at an angle of $45^{\circ}$. The hub and spokes are supported by a vertical pivot, by means of which the operator is enabled to follow the diurnal motion of the sun, while a horizontal axle, secured to the upper end of the pivot, and held by appropriate bearings under the hub, enables him to regulate the inclination to correspond with the altitude of the luminary. The heater is composed of rolled plate iron 0.017 inch thick, and provided with head and bottom formed of non-conducting materials. By means of a screw-plug passing through the bottom and entering the face of the hub the heater may be applied and removed in the course of five minutes, an important fact, as will be seen hereafter. It is scarcely necessary to state that the proportion of the ends of the conical heater should correspond with the perimeters of the reflector, hence the diameter of the upper end, at the intersection of the polygonal plane, should be to that of the lower end as 8 to 6 , in order that every part may be acted upon by reflected rays of equal density. This condition being fulfilled, the temperature communicated will be perfectly uniform. A short tube passes thrnigh the upper head of the heater, throngb which a thermometer is inserted for measuring the internal temperature. The stem being somewhat less than the bore of the tube, a small opening is formed by which the necessary equilibrium of pressure will be established with the external atmosphere. It should be mentioned that the indications of the thermometer during the experiment have been remarkably prompt, the bulb being subjected to the joint influence of radiation and convection.

The foregoing particulars, it will be found, furnish all necessary data for determining with absolute precision the diffusion of rays acting on the central vessel of the solar pyrometer. But the determination of temperature which uninterrupted solar radiation is capable of transmitting to the polygonal reflector calls for a correct knowledge of atmospheric absorption. Besides, an accurate estimate of the loss of radiant heat attending the reflection of the rays by the mirrors is indispensable. Let us consider these points separately.

Atmospheric Absorption. - The principal object of conducting the investigation during the summer solstice has been the facilities afforded for determining atmospheric absorption, the sun's zenith distance at noon being only $17^{\circ} 12^{\prime}$ at New York. The retardation of the sun's rays in passing through a clear atmosphere obviously depends on the depth penetrated; henceneglecting the curvature of the atmospheric limit-the retardation will be as the secants of the zenith distances. Accordingly, an observation of the temper ture produced $^{-}$ by solar radiation at a zenith distance whose secant is trice that of the secant of $17^{\circ} 12^{\prime}$, viz. $61^{\circ} 28^{\prime}$, determines the minimum atmospheric absorption at New York. The result of observations conducted during a series of years shows that the maximum solar intensity at $17^{\circ} 12^{\prime}$ reaches $66^{\circ} \cdot 2 \mathrm{~F}$, while at a zenith distance of $6 \mathrm{I}^{\circ} 28^{\prime}$ it is $52^{\circ} \cdot 5 \mathrm{~F}$.; hence, minimum atmospheric absorption at New York, during the summer solstice, is $66^{\circ} \cdot 2-52^{\circ} 5=13^{\circ} 7 \mathrm{~F}$, or $\frac{13.7}{66.2}=0.207$ of the sun's radiant energy where the rays enter the terrestrial atmosphere.

In order to determine the loss of energy attending the 
reflection of the rays by the diagonal mirrors, I have con- bulb. The mean result of repeated trials, all differing structed a special apparatus, which by means of a but slightly, show that the energy of the direct solar rays parallactic mechanism faces the sun at right angles during acting on the polygonal reflector is reduced 0.235 before observations. It consists principally of two s nall mirrors, reaching the heater.

manufactured of the same materials as the reflector, placed In accordance with the previous article, the investigadiagonally at right angles to each other; a thermometer tion has been based on the assumption that, the temperabeing applied between the two, whose stem points towards tures produced by radiant heat at given distances from the sun. The direct solar rays entering through perfora- its source are inversely as the diffusion of the rays at those tions of an appropriate shade, and reflected by the in- distances. In other words, the temperature produced by clined mirrors, act simultaneously on opposite sides of the solar radiation is as the density of the rays.

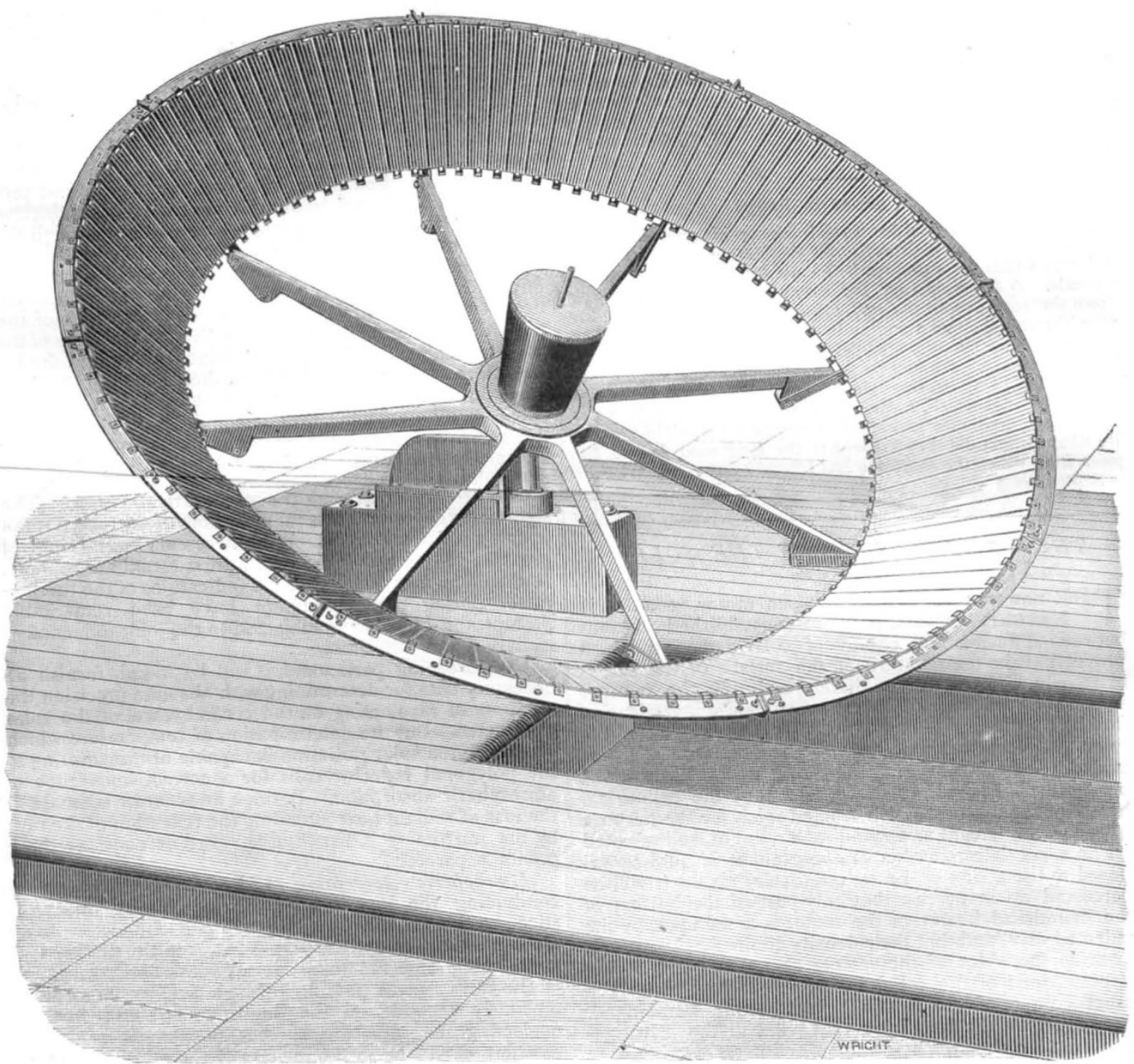

Captain Ericsson's Solar Pyrometer, erected at New York, I884.

It will be remembered that Sir Isaac Newton, in estimating the temperature to which the comet of 1630 was subjected when nearest to the sun, based his calculations on the result of his practical observations that the maximum temperature produced by solar radiation was onethird of that of boiling water. Modern research shows that the observer of 1650 underrated solar intensity only $5^{\circ}$ for the latitude of London. The distance of the comet from the centre of the sun being to the distance of the earth from the same as 6 to 1000 , the author of the "Principia" asserted that the density of the rays was as $1000^{2}$ to $6^{2}=28,000$ to $\mathrm{I}$; hence the comet was subjected to a temperature of $28,000 \times \frac{180^{\circ}}{3}=1,680,000^{\circ}$, an intensity exactly " 2000 times greater than that of redhot iron " at a temperature of $840^{\circ}$. The distance of the comet from the solar surface being equal to one-third of the sun's radius, it will be seen that, in accordance with 
the Newtonian doctrine, the temperature to which it was subjected indicated a solar intensity of $\frac{4^{2} \times 1,680,000}{3^{2}}=$ $2,986,000^{\circ} \mathrm{F}$.

The writer has established the correctness of the assumption that "the temperature is as the density of the rays," by showing practically that the diminution of solar temperature (for corresponding zenith distances) when the earth is in aphelion corresponds with the increased diffusion of the rays consequent on increased distance from the sun. This practical demonstration, however, has been questioned on the insufficient ground that " the eccentricity of the earth's orbit is too small and the temperature produced by solar radiation too low" to furnish a safe basis for computations of solar temperature.

In order to meet the objection that the diffusion of the rays in aphelion do not differ sufficiently, the solar pyrometer has been so arranged that the density, i.e. the diffusion of the reflected rays, can be changed from a ratio of $I$ in 5040 to that of $I$ in I0,24I. This has been effected by employing heaters respectively to inches and 20 inches in diameter. With reference to the "low" solar temperature pointed out, it will be perceived that the adopted expedient of increasing the density of the rays without raising the temperature by converging radiation, removes the objection urged.

Agreeably to the dimensions already specified, the area of the 10-inch heater acted upon by the reflected solar rays is $331^{\circ} .5$ square inches, the area of the 20 -inch heater being $673^{\circ} 9$ square inches. The section of the annular sunbeam whose direct rays act upon the polygonal reflector is 3130 square inches, as before stated.

Regarding the diffusion of the solar rays during the investigation, the following demonstration will be readily understood. The area of a sphere whose radius is equal to the earth's distance from the sun in aphelion being to the sun's area as $218^{8} \mathrm{I}^{2}$ to I, while the reflector of the solar pyrometer intercepts a sunbeam of 3130 square inches section, it follows that the reflector will receive the radiant heat developed by $\frac{3^{1} 30}{218^{\circ} 1^{2}}=0.065^{2}$ square inch of the solar surface. Hence, as the ro-inch heater presents an area of $33 I^{\circ} 65$ square inches, we establish the fact that the reflected solar rays, acting on the same, are diffused in the ratio of $33 \mathrm{I}^{\circ} 65$ to $0.065^{8}$, or $\frac{3.3 \mathrm{I}^{\circ} 65}{0.065^{8}}=5040$ to $\mathrm{I}$; the

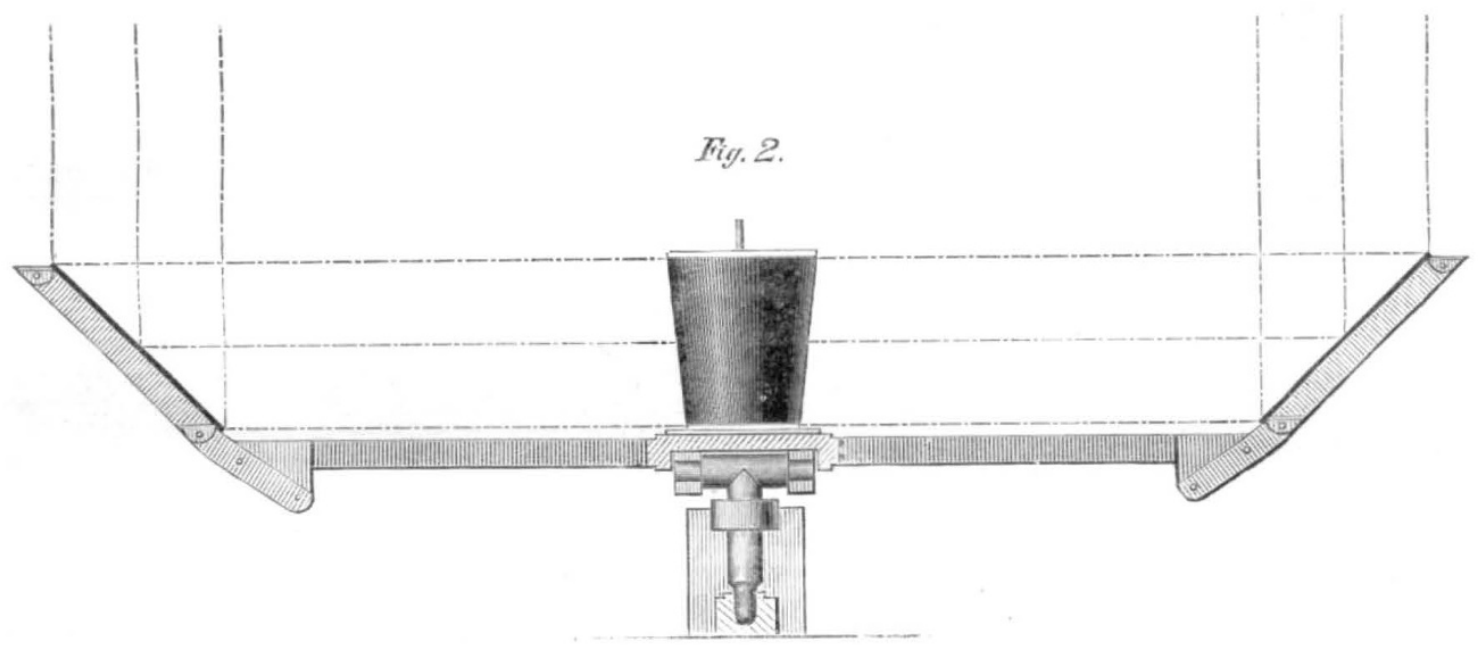

diffusion of the rays acting on the 20 inch heater being as $673^{\circ} 9$ to 0.0658 , or $\frac{6739}{0.065^{\circ}}=10,241$ to $\mathrm{I}$.

The atmospheric conditions having proved unfavourable during the investigation, maximum solar temperature was not recorded. Accordinglv, the heaters of the solar pyrometer did not reach maximum temperature, the highest indication by the thermometer of the small heater being $336^{\circ} .5$, that of the large one being $200^{\circ} 5$ above the surrounding air. No compensation will, however, be introduced on account of deficient solar lieat, the intention being to base the computation of solar emperature solely on the result of observations conducted at New York during the summer solstice of $\mathrm{I} 884$. It will be noticed that the temperature of the large heater is proportionally higher than that of the small heater, a fact showing that the latter, owing to its higher temperature, loses more heat by radiation and convection than the former. Besides, the rate of cooling of heated bodies increases more rapidly than the augmentation of temperature.

The loss occasioned by the imperfect reflection of the mirrors, as before stated, is 0'235 of the energy transmitted by the direct solar rays acting on the polygonal reflector, hence the temperature which the solar rays are capable of imparting to the large heater will be $200^{\circ} .5 \times \mathrm{I}^{\circ} 235=$ $247^{\circ} 617$; but the energy of the solar rays acting on the reflector is reduced 0.207 by atmospheric absorption, consequently the ultimate temperature which the sun's radiant energy is capable of imparting to the heater is $1.207 \times$ $247^{\circ} 6 \mathrm{I} 7=298^{\circ} .87 \mathrm{~F}$. It is hardly necessary to observe that this temperature (developed by solar radiation diffused fully ten-thousandfold) must be regarded as an actual temperature, since a perfectly transparent atmosphere, and a reflector capable of transmitting the whole energy of the sun's rays to the heater, would produce the same.

The result of the experimental investigation carricd out during the summer solstice of 1884 may be thus briefly stated. The diffusion of the solar rays acting on the 20 inch heater being in the ratio of $I$ to IO,24I, the temperature of the solar surface cannot be less than $298^{\circ} .87$ $\times 10,241=3,060,727^{\circ} \mathrm{F}$. This underrated computation must be accepted unless it can be shown that the temperature produced by radiant heat is not inversely as the diffusion of the rays. Physicists who question the existence of such high solar temperature should bear in mind that in consequence of the great attraction of the solar mass, hydrogen on the sun's surface raised to a temperature of $4000^{\circ} \mathrm{C}$., will be nearly twice as heavy as hydrogen on the surface of the earth at ordinary atmospheric temperatures; and that, owing to the immense depth of the solar atmosphere, its density would be so enormous at the stated 
low temperature that the observed rapid movements within the solar envelope could not possibly take place. It scarcely needs demonstration to prove that extreme tenuity can alone account for the extraordinary velocities recorded by observers of solar phenomena. But extreme tenuity is incompatible with low temperature and the pressure produced by an atmospheric column probably exceeding 50,000 milcs in height subjected to the sun's powerful attraction, diminished only one-fourth at the stated elevation. These facts warrant the conclusion that the high temperature established by our investigation is requisite to prevent undue density of the solar atmosphere.

It is not intended at present to discuss the necessity of tenuity with reference to the functions of the sun as a radiator; yet it will be proper to observe that on merely dynamical grounds the enormous density of the solar envelope which would result from low temperature, presents an unanswerable objection to the assumption of Pouillet, Vicaire, Sainte-Claire Deville, and other eminent savants, that the temperature of the solar surface does not reach $3000^{\circ} \mathrm{C}$.

J. ERICSSON

\section{THE BRITISH ASSOCIATION}

$\mathrm{H}$ OSTS and guests have been abundantly satisfied with the results of the Canadian Meeting of the British Association. The Canadians have done their very utmost for their guests, and the latter appear to have responded heartily. There have been, to judge from the very full reports in the Times, some notable incidents in connection with the meeting, which will no doubt be fully noticed in the reports from our Special Correspondents, which we hope to receive in time for next week's number.

The General Committee met on Wednesday, with Lord Rayleigh in the chair. The aggregate membership was reported as 1773 , of whom 558 were old and 1215 new. The following are the grants of money that have been made :-

Mathematical Section.-Meteorological observations near Chepstow, 25l.; synoptic charts of the Indian Ocean, $50 l$.; reduction of tidal observations, $10 l$. ; calculation of mathematical tables, Iool.; meteorological observations on Ben Nevis, 5ol.; solar radiation, 20l.; meteoric dust, 70 l.

Chemical Section.--Vapour pressures and refractive indices of salt solutions, $25 l$; chemical nomenclature, $5 l$. ; physical constants of solutions, $20 l$.

Geological Section.-Volcanic phenomena of Vesuvius, 25l.; Raygill fissure, $15 l$.; earthquake phenomena of Japan, 75l.; fossil Phyllopoda of the Palæozoic rocks, 25l.; fossil plants of British Tertiary and Secondary beds, 5ol.; Geological Record, 50l.; erosion of seacoasts, rol.; circulation of underground waters, $10 l$.

Biological Section.--Table at Naples Zoological Station, IOOl.; Zoological Record, Iool.; migration of birds, 3ol.; exploring Kilimanjaro and adjoining mountains of Equatorial Africa, 25l. ; recent Polyzoa, Iol.; marine biological station at Granton, Iool.; biological stations on coast of United Kingdom, I $50 l$.

Geographical Section.-Exploring New Guinea, 20ol.; exploring Mount Roraima, rool.

Mechanical Section.--Patent legislation, $5 l$.

Anthropological Section.-Investigating the characteristic physical and other features of north-west tribes of Canada, 50l.; physical characteristics of the races in the British Isles, Iol. Total, I $525 l$.

In the case of the following Committees no moncy grants were voted :-Committees on practical standards for use in electrical measurements, for promoting tida observations in Canada, for calculating tables of fundamental variations of algebraic forms, for securing harmonic analysis in reducing tidal observations, for com- paring and reducing magnetic observations, for investigating the rate of increase of underground temperatures, for securing an international geological map of Europe, for reporting on erratic blocks of England, Wales, and Ireland, for examining marine life on coasts and rivers of North America, for survey of Palestine, and for science teaching in elementary schools. A vote was passed that the Council be recommended to request the Admiralty to adopt an harmonic analysis for the reduction of tidal observations. This is already being done in Germany, France, India, and elsewhere. A letter was read on the subject prepared by Sir William Thomson and Prof. G. $H$. Darwin to send to the Admiralty. The Council was also recommended to request the Canadian Government to adopt measures for investigating the physical character, languages, social and artistic condition of the native tribes of the Dominion. Various American members having suggested that an International Scientific Congress be formed, this subject was referred to the Committee by several Sections.

The General Committee adjourned to meet in London on November I I.

The closing meeting of the Association was held in Queen's Hall the same afternoon. There was a large attendance, Lord Rayleigh being in the chair. Admiral Ommanney, the acting treasurer, announced the membership, and also the total receipts, which have been about I80ol. The suggestion as to an International Scientific Congress was received with applause.

The Corporation and Faculty of McGill University were on the platform, and Sir William Dawson, the Principal, after a brief preliminary address, conferred the honorary degree of LL.D. upon the leading members of the Association, whose names have already been given. As the diplomas were delivered, warm applause greeted each recipient.

Lord Rayleigh thanked the University for the honours conferred and also for the splendid hospitality given to the Association, the recollection of which they would retain during the remainder of their lives. He said that no previous meeting had been so well provided with meeting-rooms as the University furnished. As a slight token of acknowledgment for Montreal's reception, the Association had provided a gold medal and endowment for McGill University, although he felt they could never fully appreciate the generosity of their hosts.

Sir Richard Temple moved, and Prof. Boyd Dawkins seconded, a resolution expressing cordial sympathy with the popular movement set on foot in Montreal to establish a public library worthy of the great city to properly mark the occasion of the first meeting of the British Association in Canada. Both made brief addresses, urging the members to aid the project. Sir William Thomson spoke in its advocacy, saying that a good library would be of vast importance to Montreal and to this portion of North America, that it would be an excellent basis for the subsequent establishment of a good scientific school. $\mathrm{He}$ urged the members to give liberal subscriptions. The resolution was adopted amid applause.

Sir Lyon Playfair moved, and General Lefroy seconded, a resolution of cordial thanks to the Dominion Government for the aid, support, and sympathy shown in promoting the Montreal meeting of the British Association, and for the warm interest felt in its success, which was adopted. Mr. J. White, a member of the Canadian House of Commons, responded for the Dominion Government.

Sir William Thomson moved, and Sir Frederick Bramwell seconded, a resolution of thanks to the McGill University, the Corporation of Montreal and its citizens, with a long list of other bodies who aided in promoting the objects of the meeting. Sir James Ferrier responded, saying, in the course of a felicitous address, that already the projected public library had been fairly started by a 